Article

\title{
Photocatalytic Activities of Copper Doped Cadmium Sulfide Microspheres Prepared by a Facile Ultrasonic Spray-Pyrolysis Method
}

\author{
Jinzhan Su *, Tao Zhang, Yufeng Li, Yubin Chen and Maochang Liu \\ International Research Center for Renewable Energy, State Key Laboratory of Multiphase Flow in Power \\ Engineering, Xi'an Jiaotong University, No. 28, Xianning West Road, Xi'an 710049, Shaanxi, China; \\ zt.268@stu.xjtu.edu.cn (T.Z.); lyf1127@stu.xjtu.edu.cn (Y.L.); ybchen@mail.xjtu.edu.cn (Y.C.); \\ maochangliu@mail.xjtu.edu.cn (M.L.) \\ * Correspondence: j.su@mail.xjtu.edu.cn; Tel.: +86-29-8266-8296 \\ Academic Editor: Nick Serpone \\ Received: 9 May 2016; Accepted: 2 June 2016; Published: 15 June 2016
}

\begin{abstract}
Ultrasonic spray pyrolysis is a superior method for preparing and synthesizing spherical particles of metal oxide or sulfide semiconductors. Cadmium sulfide (CdS) photocatalysts with different sizes and doped-CdS with different dopants and doping levels have been synthesized to study their properties of photocatalytic hydrogen production from water. The CdS photocatalysts were characterized with scanning electron microscopy (SEM), X-ray fluorescence-spectrometry (XRF), UV-Vis absorption spectra and X-ray diffraction (XRD) to study their morphological and optical properties. The sizes of the prepared CdS particles were found to be proportional to the concentration of the metal nitrates in the solution. The CdS photocatalyst with smaller size showed a better photocatalytic activity. In addition, $\mathrm{Cu}$ doped $\mathrm{CdS}$ were also deposited and their photocatalytic activities were also investigated. Decreased bandgaps of CdS synthesized with this method were found and could be due to high density surface defects originated from $\mathrm{Cd}$ vacancies. Incorporating the $\mathrm{Cu}$ elements increased the bandgap by taking the position of $\mathrm{Cd}$ vacancies and reducing the surface defect states. The optimal Cu-doped level was found to be $0.5 \mathrm{~mol} \%$ toward hydrogen evolution from aqueous media in the presence of sacrificial electron donors $\left(\mathrm{Na}_{2} \mathrm{~S}\right.$ and $\left.\mathrm{Na}_{2} \mathrm{SO}_{3}\right)$ at a $\mathrm{pH}$ of 13.2. This study demonstrated that ultrasonic spray pyrolysis is a feasible approach for large-scale photocatalyst synthesis and corresponding doping modification.
\end{abstract}

Keywords: CdS; doping; photocatalytic; spray pyrolysis

\section{Introduction}

Photocatalytic water splitting has continuously been a hot academic topic since Fujishima and Honda's work in hydrogen production from water using a $\mathrm{TiO}_{2}$ electrode [1]. Over the past decades, metal sulfides [2] and chalcogenides [3] have attracted broad interest from scientists engaged in photocatalysis. Of those compounds, cadmium sulfide (CdS) is an attractive semiconductor photocatalyst under continuous research due to its optimal band gap and suitable position of the conduction band and valence band edge [4-6]. Various CdS nanostructures or combinations were applied as photocatalysts for solar hydrogen production [7-9]. One drawback of this material is the photocorrosion by the photogenerated holes from the valence band of the CdS during the photocatalytic reaction in aqueous solution. In order to overcome the inherent disadvantages of CdS photocatalyst for hydrogen production, hybrid composites or solid solution based on CdS have been explored to improve the separation of photogenerated holes and electrons as well as their stabilities, and thus promote the overall photocatalytic activity [10-15]. Some photocatalysts with unique structure show promising efficiency and potential for large scale photocatalytic water splitting application [16]. Many novel 
methods have been applied for preparing and synthesizing CdS particles. Bao et al. [17] prepared nanoporous CdS nanostructrues by method of self-templanted synthesis, having a high hydrogen yield under visible light irradiation. Many other techniques such as hydrothermal method [18], thermal evaporation [19], biogenic synthesis [20], chemical bath deposition [21] were applied to prepare CdS nanostructures. It is reported that spray pyrolysis is an efficient way to prepare sulfides or oxides microspheric powder or films [22-24]. With this method, one can synthesize micro-particles of different sizes which range from submicrometers to micrometers by controlling the various concentrations of metal nitrates in their starting aqueous solution. Kikuo Okuyama et al. [22] prepared CdS fine particles with different particle sizes by an Ultrasonic spray-pyrolysis method. In Kikuo's work, ZnS and CdS fine particles with different particle sizes have been prepared and the effects of temperature profile in the reactor furnace and concentration of the metal nitrates in the solution on the properties of prepared particles were also investigated.

Doping is a viable approach for modulating electrical, optical or photocatalytical properties of photocatalyst [25]. It can be used to reduce the band gap of photocatalyst by forming intermediate bands [26] or improve the chemical stability by injecting the holes into the formed acceptor energy level and reduce their activity on photocorrosion. [27] In our previous report, Cu doped CdS thin films were deposited by ultrasonic spray pyrolysis (USP). The non-uniform distribution of Cu atoms in the host CdS films formed disordered local p-n junctions which facilitate charge separation [28].

In addition, it has been reported that the USP method is a simple and cost-effective technique to prepare photocatalyst with different doping levels. A. Rmili et al. [29] prepared the undoped and Ni-doped CdS thin films with various doping levels by spray pyrolysis technique. The spray pyrolysis technique is considered as one of the most promising techniques for producing large scale inexpensive CdS catalyst for massive solar hydrogen application.

In this study, we synthesized the spherical CdS nanoparticles with different sizes profile and Cu doped CdS photocatalyst with different doping levels by ultrasonic spray pyrolysis. The dopants were added directly into the precursor for spray pyrolysis. The temperature in the tube-furnace was kept constant while the concentrations of metal nitrates, dopants and in the precursors containing $\mathrm{Cd}\left(\mathrm{NO}_{3}\right)_{2} \cdot 4 \mathrm{H}_{2} \mathrm{O}$ and $\mathrm{SC}\left(\mathrm{NH}_{2}\right)_{2}$ were adjusted to change the particle size or doping level. The UV-Vis absorption spectrum, crystalline phase, fluorescence properties and photocatalystic activities of CdS or doped CdS photocatalysts were tested to investigate the effect of particle-sizes, dopant and doping level on their structural, optical and photocatalytic properties.

\section{Results and Discussion}

\subsection{Morphological, Optical and Structural Properties of Undoped CdS Particles}

Figure 1 shows SEM images of spherical CdS particles obtained from different starting-solution concentrations at a constant pyrolysis temperature of $500{ }^{\circ} \mathrm{C}$. It was found that the particle sizes increase with increasing starting-solution concentration and the surface of CdS particles is rather rough because it originates from aggregation of primary particles [22]. In addition, it is observed that the CdS particles prepared with same concentration possess different sizes. This can be due to the collision between precursor droplets and creating droplets with different sizes during the deposition. However, the average particle size can be controlled by changing the concentration of the starting solution. The TEM images shown in Figure 1d confirmed the rough surface of CdS particles and ununiformed sizes of obtained CdS particles.

Figure 2 shows the UV-Vis absorption spectra of prepared CdS nanoparticles with different starting-solution concentrations. The direct band gap $\left(\mathrm{E}_{\mathrm{g}}\right)$ can be determined using the Tauc relation given by [30]:

$$
(\alpha \mathrm{h} v)^{2}=\mathrm{A} \times\left(\mathrm{h} v-\mathrm{E}_{\mathrm{g}}\right)
$$

where $\mathrm{A}$ is a constant, $\alpha$ is the absorption coefficient, and hv is the photon energy. The intersection with the $\mathrm{x}$-axis of the plot of $(\alpha \mathrm{h} v)^{2}$ versus hv corresponds to the optical gap $\mathrm{E}_{\mathrm{g}}$. The bandgaps of CdS 
with precursor solution concentrations of $0.1 \mathrm{~mol} / \mathrm{L}, 0.5 \mathrm{~mol} / \mathrm{L}$ and $1.0 \mathrm{~mol} / \mathrm{L}$ were determined to be $2.31 \mathrm{eV}, 2.28 \mathrm{eV}$ and $2.25 \mathrm{eV}$, respectively. These values are all smaller than the typical value for bulk $\mathrm{CdS}$ sample (about $2.4 \mathrm{eV}$ ) and this red shift increased with increasing starting-solution concentration. The red shift could originate from the surface defects of the CdS nanoparticles [31], that is because the defect states could underestimate bandgap energy for samples containing such defects.

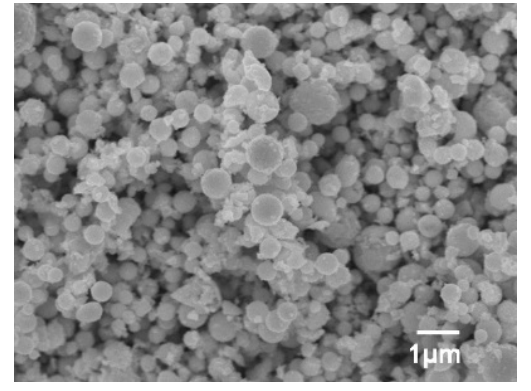

(a)

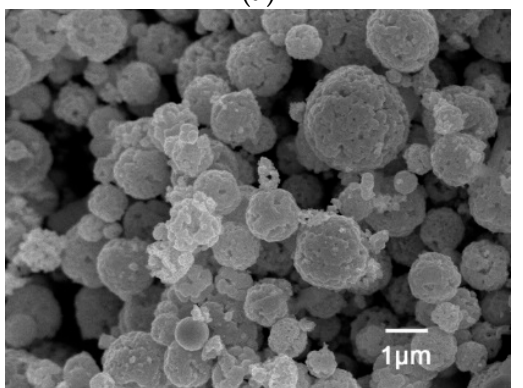

(c)

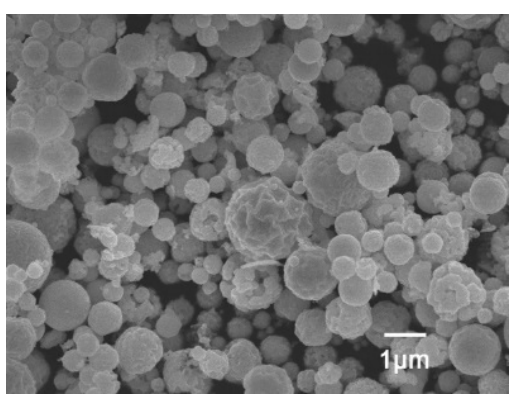

(b)

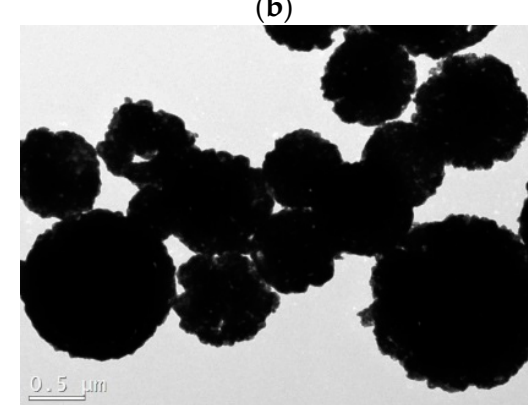

(d)

Figure 1. Scanning electron microscope images of CdS particles obtained from different starting-solution concentrations: (a) $0.1 \mathrm{~mol} / \mathrm{L}$; (b) $0.5 \mathrm{~mol} / \mathrm{L}$; (c) $1.0 \mathrm{~mol} / \mathrm{L}$ and (d) TEM images of CdS particles with concentrations of $1.0 \mathrm{~mol} / \mathrm{L}$.

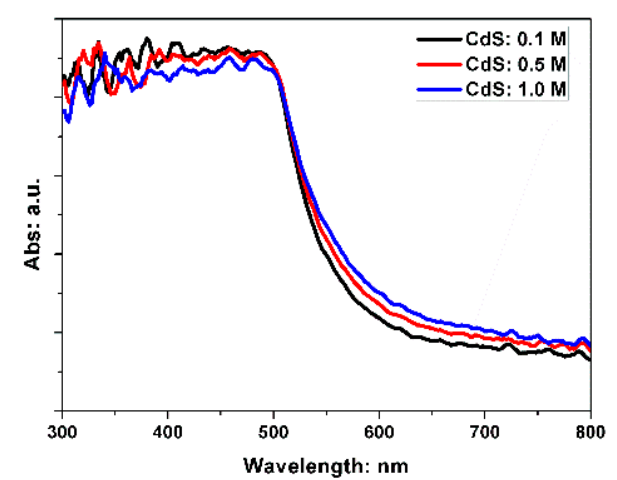

(a)

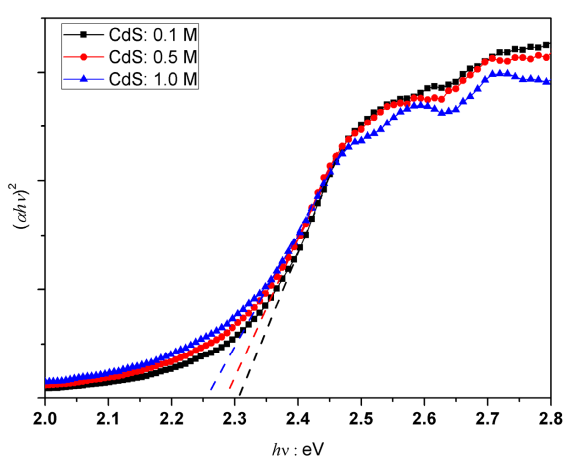

(b)

Figure 2. The UV-Vis absorption spectra (a) and corresponding Tauc plot (b) of CdS with different starting-solution concentrations.

Figure 3a shows XRD patterns of the CdS particles obtained from different solution concentrations at a constant temperature. No effect of precursor concentration on the structural phase was found. The hexagonal phase of CdS particles with good crystallinity were obtained for all precursor concentrations. The capabilities of $\mathrm{H}_{2}$ evolution of $\mathrm{CdS}$ with different precursor concentrations are shown in Figure $3 b$. The results indicate that the activity of $\mathrm{H}_{2}$ evolution and the stability are clearly improved with the decrease of the CdS particle size, which could be due to a higher surface area in smaller CdS particles synthesized by a lower concentration precursor than that of larger ones. 


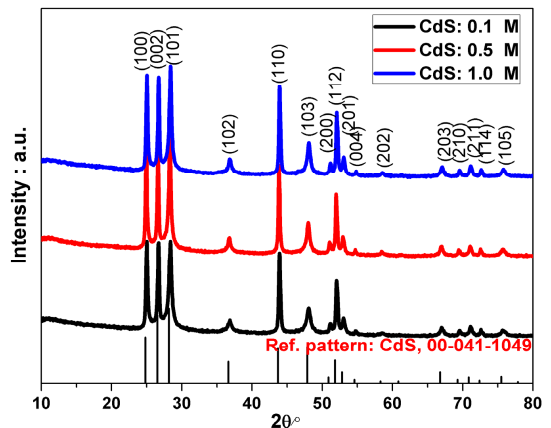

(a)

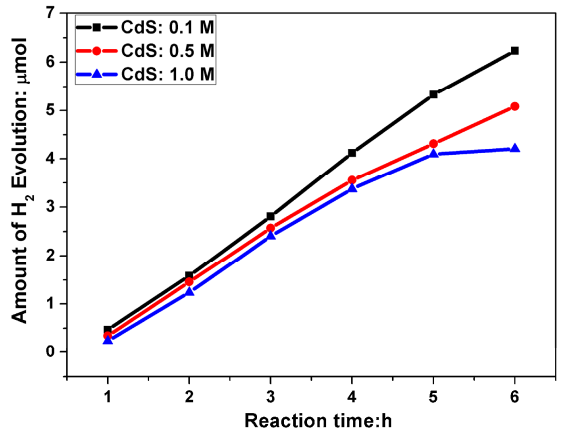

(b)

Figure 3. The crystal structure and performance. (a) X-ray diffraction patterns and (b) hydrogen evolution rate of CdS particles prepared at different starting-solution concentrations: $0.1 \mathrm{~mol} / \mathrm{L}$, $0.5 \mathrm{~mol} / \mathrm{L}$ and $1.0 \mathrm{~mol} / \mathrm{L}$.

\subsection{Morphological, Optical and Structural Properties of $\mathrm{Cu}$ Doped CdS Particles}

To investigate the doping effect on the photocatalytic activity of CdS particles, we doped CdS with $\mathrm{Cu}$ at doping levels of $0.2 \mathrm{~mol} \%, 0.5 \mathrm{~mol} \%$ and $1.0 \mathrm{~mol} \%$. to adjust its structural, electrical, and optical properties. In order to facilitate the identification of $\mathrm{Cd}, \mathrm{Cu}$ and $\mathrm{S}$ in the $\mathrm{Cu}$-doped $\mathrm{CdS}$ samples, X-ray fluorescence-spectrometry of $1.0 \% \mathrm{Cu}$-doped CdS was studied. To avoid the misleading that may result from the detection limit of the method, only results for $1.0 \% \mathrm{Cu}$-doped sample was presented. Table 1 shows XRF data of $1.0 \% \mathrm{Cu}$-doped CdS particles. From Table 1, one can see that the ratio of $\mathrm{Cu}$ to $\mathrm{Cd}$ is 0.01 which means that it is very precise to control element doping level by precursor composite adjustment in ultrasonic spray pyrolysis method. We can also find that there should be a high density of $C d$ vacancy $\left(V_{C d}\right)$ as the mol ration of $S$ is much higher than that of $C d$. Since the formation energies of $\mathrm{Cu}$ substitutional defect $\left(\mathrm{Cu}_{\mathrm{Cd}}\right)$ is smaller than $\mathrm{Cd}$ vacancy $\left(\mathrm{V}_{\mathrm{Cd}}\right)$, presence of $\mathrm{Cu}$ in the sample is expected to eliminate the $\mathrm{V}_{\mathrm{Cd}}$ defect [32].

Table 1. X-ray fluorescence-spectrometry (XRF) analysis result of $1.0 \% \mathrm{Cu}$-doped $\mathrm{CdS}$.

\begin{tabular}{ccccc}
\hline Title & $\mathbf{C u}$ & $\mathbf{C d}$ & $\mathbf{S}$ & $\mathbf{O}$ \\
\hline Intensity (KCps) & 11.0 & 346.3 & 223.3 & 0.1 \\
wt \% & 0.385 & 66.7 & 27.5 & 5.46 \\
$\mathrm{~mol} \mathrm{\%}$ & 0.335 & 32.965 & 47.74 & 18.957 \\
\hline
\end{tabular}

Figure 4a shows XRD patterns of CdS paticles of different $\mathrm{Cu}$-dopants levels with ratio of $\mathrm{Cu}$ to $\mathrm{Cd}: 0.0 \%, 0.2 \%, 0.5 \%$ and $1.0 \%$. No change of XRD pattern was observed between CdS particles with different $\mathrm{Cu}$-doping levels, This could be due to the small doping level that does not affect the hexagonal phase of the CdS particles. The average crystalline sizes of $\mathrm{Cu}$ doped samples were estimated from the XRD patterns using the Scherrer equation [33]. The crystallite sizes calculated using the Scherrer equations are $111.5 \mathrm{~nm}, 77.4 \mathrm{~nm}, 77.0 \mathrm{~nm}$ and $76.8 \mathrm{~nm}$ for $0 \%, 0.2 \%, 0.5 \%$ and $1 \%$ doped samples, respectively. The decrease of crystallite size could result from the presence of $\mathrm{Cu}$ in the doped samples which causes restriction to the growth of $\mathrm{CdS}$ nanoparticles during the pyrolysis process [34]. To further investigate valence state of $\mathrm{Cu}$, XPS is carried out and the XPS profile of $\mathrm{Cu}$ $2 p$ is presented in Figure $4 b$. The $\mathrm{Cu} 2 \mathrm{p}_{1 / 2}(949.6 \mathrm{eV})$ and $\mathrm{Cu} 2 \mathrm{p}_{3 / 2}(929.6 \mathrm{eV})$ lines verify that the $\mathrm{Cu}$ exists as $\mathrm{Cu}^{2+}$ [35]. The SEM images of CdS particles of different $\mathrm{Cu}$-dopants levels were also obtained to check the doping influence on the morphology and size of CdS particles. It was clearly shown in Figure 5 that the doping increased the porosity compared to the undoped one as shown in Figure $1 \mathrm{~b}$. However, the porosity showed no significant changes at different doping level and the average particle sizes scarcely changed for different samples.

The influence of $\mathrm{Cu}$ doping on the band gaps of CdS particles were investigated by the UV-Vis absorption spectra. Figure 6 shows the UV-Vis absorption spectra of $\mathrm{Cu}$-doped prepared by ultrasonic spray pyrolysis at various molar ratio of $\mathrm{Cu} / \mathrm{Cd}$. It can be seen that all the samples show a visible-light absorption region from $500 \mathrm{~nm}$ to $560 \mathrm{~nm}$, and slight blue shifts of the absorption edge of Cu-doped 
CdS particles were observed comparing to pure CdS particles. The band gaps of pure CdS particles and $\mathrm{Cu}$-doped CdS can be calculated by the Tauc plots as shown in Figure 6b. It was found that the band gaps of doped CdS increased with higher $\mathrm{Cu}$ doping concentration. Since copper sulfide possesses a lower band gap compared to CdS, any possibility of CuS formation can be ruled out. The $\mathrm{Cu}$ element did not decrease the band gaps of CdS by forming new levels; however, it can cause the band gap increase which could originate from quantum effects of the decreasing of crystallite size after $\mathrm{Cu}$ doping [36,37]. The high density defect of CdS nanoparticles synthesized by pyrolysis method narrowed the band gaps of CdS (shown in Figure 2) by creating defect states in the band gap, while $\mathrm{Cu}$ doping increased the band gaps of CdS particles which shift the band gaps back towards the typical value for bulk CdS sample.
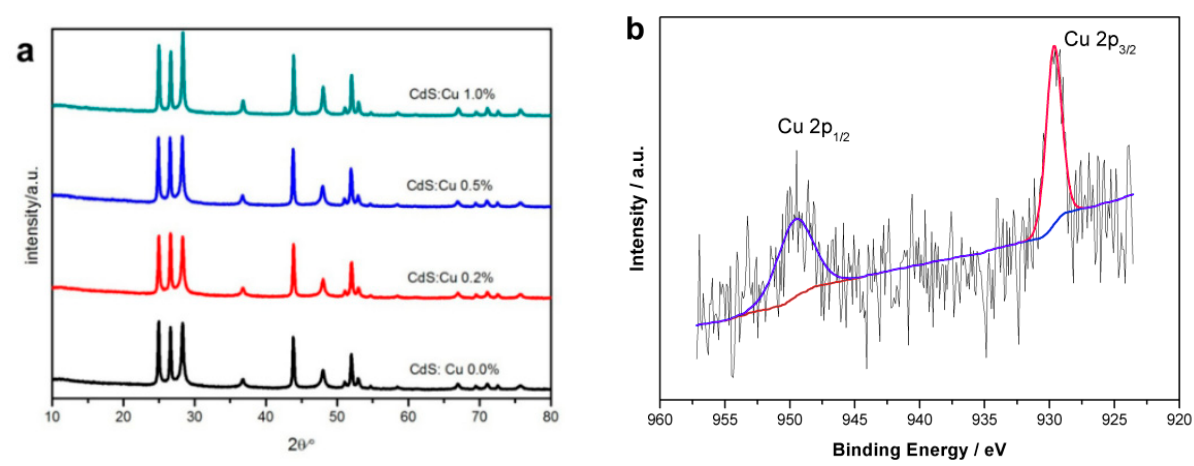

Figure 4. The crystal structure of doped CdS particles and electronic structure of dopant. (a) X-ray diffraction patterns of $\mathrm{CdS}$ particles of different $\mathrm{Cu}$-dopants levels in the same concentration of starting-solution: $0.0 \%, 0.2 \%, 0.5 \%$ and $1.0 \%$; (b) XPS profile of $\mathrm{Cu}^{2+}$ in $0.5 \%$ Cu-doped CdS particles.

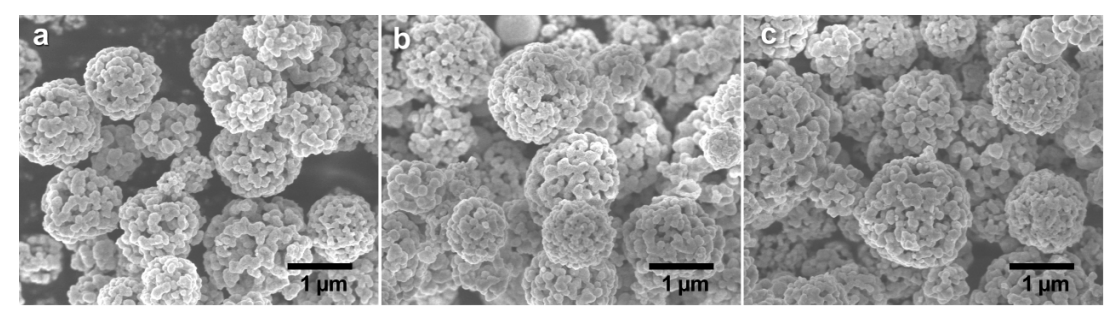

Figure 5. Scanning electron microscope images of $\mathrm{Cu}$-doped prepared at various molar ratio of $\mathrm{Cu} / \mathrm{Cd}$ : (a) $0.2 \%$; (b) $0.5 \%$ and (c) $1.0 \%$.

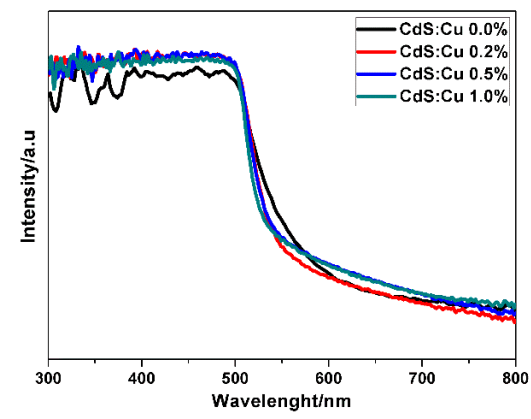

(a)

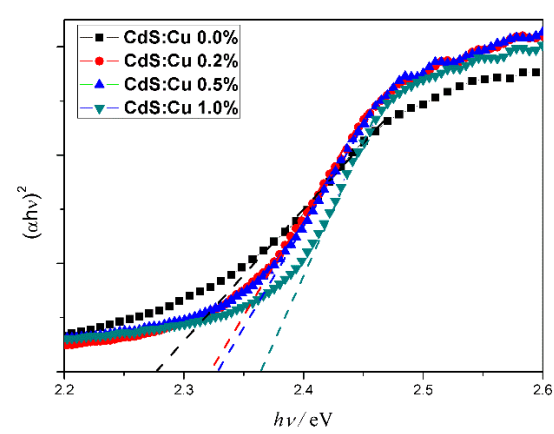

(b)

Figure 6. The optical properties of doped CdS particles. (a) UV-Vis absorption spectra and; (b) Tauc plot of $\mathrm{Cu}$-doped prepared at various molar ratio of $\mathrm{Cu} / \mathrm{Cd}: 0.0 \%, 0.2 \%, 0.5 \%$ and $1.0 \%$.

Photoluminescence (PL) spectra were used to study the optical characteristic of CdS after doping. PL spectra of the CdS particle with different doping levels were recorded with a $340 \mathrm{~nm}$ excitation wavelength and the results are shown in Figure 7. For pure CdS, it is obvious that there is a PL peak 
centered at $410 \mathrm{~nm}$, this peak is the excitonic emission of CdS [34]. Another peak for pure CdS is a peak centered at $550 \mathrm{~nm}$ in the section of visible light. This peak can be attributed to charge carrier recombination at surface states of obtained $\mathrm{CdS}$ [34]. This recombination was reported as a radiative recombination of free charge carrier and trapped charge carriers at surface defects [38,39].

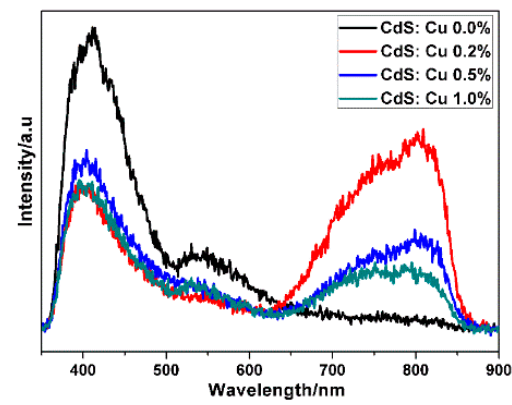

Figure 7. Photoluminescence spectra of the different levels Cu-doped CdS particle: $0.0 \%, 0.2 \%, 0.5 \%$ and $1.0 \%$ (excitation wavelength: $340 \mathrm{~nm}$ ).

The surface states in CdS could arise from sulfur vacancies or cadmium vacancies. According to the rich sulfur source synthesis condition and XRF results, the surface states could result from Cd vacancies, which can act as hole trap states [40]. For the $\mathrm{Cu}$-doped $\mathrm{CdS}$ particles, excitonic emissions as well as surface state emission decreased after $\mathrm{Cu}$ doping; however, a new broad peak range from $650 \mathrm{~nm}$ to $850 \mathrm{~nm}$ emerged. This emission peak is clearly a Cu-related emission, which could be the $\mathrm{Cu}$ acceptor level (T2 level) originated from the triplet state of $\mathrm{Cu}^{2+}$ [41]. With increase of doping level from $0.2 \%$ to $1 \%$, this emission intensity decreased which could be the result of increasing nonradiative transitions from T2 level to the valence band of CdS with increase of Cu concentration in CdS [34].

The amount of hydrogen evolution with different $\mathrm{Cu}$-doping levels of $\mathrm{CdS}$ particles is shown in Figure 8. It can be seen that hydrogen production rate of all three $\mathrm{Cu}$-doped $\mathrm{CdS}$ samples are higher than that of pure CdS, and the $0.5 \% \mathrm{Cu}$-doped sample shows the highest hydrogen production rate. Doping is often used to improve absorption efficiency by shifting absorption edge to visible light. However, in our case, $\mathrm{Cu}$ doping did not narrow the bandgaps of $\mathrm{CdS}$, as discussed in the previous section. It was reported that the $\mathrm{Cd}^{2+}$ are substituted by $\mathrm{Cu}^{+}$in unit cells of $\mathrm{CdS}$ [42]. With the increase of $\mathrm{Cu}$ doping, there will be an increase of $\mathrm{Cu}$ atoms substituted for $\mathrm{Cd}$ sites, acting as acceptors and giving rise to $\mathrm{p}$ type conductivity [43]. At the same time, surfaces with a state originating from $\mathrm{Cd}$ vacancy and acting as recombination center decreased, and thus the photocurrent improved. When the doping level is higher than $0.5 \mathrm{~mol} \%$, a further increase of $\mathrm{Cu}$ doping increased the nonradiative transitions from $\mathrm{T} 2$ level to the valence band of $\mathrm{CdS}$ and caused a higher charge recombination rate at the $\mathrm{Cu}$ sites and thus a decrease of photocatalytic performance.

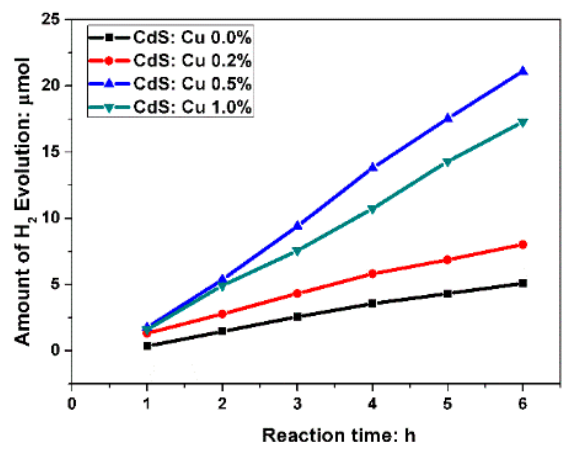

Figure 8. Amount of hydrogen evolution form water with different $\mathrm{Cu}$-doping levels CdS particles: $0.0 \%, 0.2 \%, 0.5 \%$ and $1.0 \%$. 


\section{Materials and Methods}

Analytical grade $\mathrm{Cd}\left(\mathrm{NO}_{3}\right)_{2} \cdot 4 \mathrm{H}_{2} \mathrm{O}, \mathrm{SC}\left(\mathrm{NH}_{2}\right)_{2}$ and $\mathrm{Cu}\left(\mathrm{NO}_{3}\right)_{2} \cdot 3 \mathrm{H}_{2} \mathrm{O}$ were used as received. The precursor for each spray pyrolysis synthesis of undoped CdS particle was prepared by dissolving $\mathrm{Cd}\left(\mathrm{NO}_{3}\right)_{2} \cdot 4 \mathrm{H}_{2} \mathrm{O}$ and $\mathrm{SC}\left(\mathrm{NH}_{2}\right)_{2}$ in $100 \mathrm{~mL}$ deionized water to reach a concentration of $0.5 \mathrm{~mol} / \mathrm{L}$ $(\mathrm{pH}=4.1)$ in a beaker. For the precursor for spray pyrolysis synthesis of metal doped CdS particle, certain amount of metal $(\mathrm{Cu}, \mathrm{Ni}$ or $\mathrm{Pb})$ nitrates were added into obtained $100 \mathrm{~mL}$ precursors to make the metal $(\mathrm{Cu}, \mathrm{Ni}$ or $\mathrm{Pb})$ to $\mathrm{Cd}$ molar ratio at 0.005 . The $\mathrm{CdS}$ particles with different $\mathrm{Cu}$ doping level (Cu to Cd molar ratio: 0.002, 0.005 and 0.01) were also synthesized by adding different amount of Copper nitrate. The obtained precursors for different samples were transferred to a custom-made ultrasonic nebulizer (with a frequency of $1.72 \mathrm{MHz}$ ), in which the precursor was atomized into micro-droplet and carried into a $500^{\circ} \mathrm{C}$ tube-furnace by flowing Nitrogen. Upon pyrolysis reaction, CdS or doped CdS spherical micro-particles were formed and settled on the inner wall of the tube-furnace. The micro-particles were then collected, washed with ethanol and dried in vacuum at $100{ }^{\circ} \mathrm{C}$ for about $8 \mathrm{~h}$. The schematic diagram of ultrasonic spray pyrolysis system for CdS spherical micro-particles preparation is shown in Figure 9.

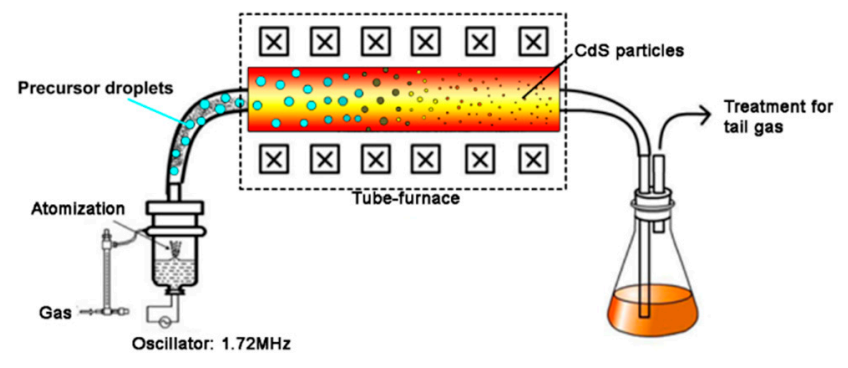

Figure 9. Schematic drawing of ultrasonic spray pyrolysis system for synthesis of $\mathrm{Cu}$ doped CdS.

The structural and optical properties of CdS particles obtained by ultrasonic spray pyrolysis method were examined by scanning electron microscopy (SEM, model JSM-6700, JEOL, Tokyo, Japan), X-ray fluorescence-spectrometry (XRF, 4KW, RhK $\alpha$ Bruker AXS, Karlsruhe, Germany), UV-Visible spectrophotometer (Hitachi U-4100, Tokyo, Japan), X-ray diffraction (CuK $\alpha, 40 \mathrm{KV}, 40 \mathrm{~mA}$, PANalytical BV, Almelo, The Netherlands) and Photoluminescence (PTI QuantaMaster ${ }^{\mathrm{TM}} 40$, Photon Technology International, Lawrenceville, NJ, USA).

Photocatalytic hydrogen evolution was performed in a gas-closed system with a side irradiation Pyrex cell at $35^{\circ} \mathrm{C}$. The $12.56 \mathrm{~cm}^{2}$ side window of the cell was irradiated with a PLS-SXE300/300UV Xe lamp through a cutoff filter $(>430 \mathrm{~nm}, \mathrm{~T}=65 \%) .0 .2 \mathrm{~g}$ photocatalysts powder was dispersed by a magnetic stirrer in an aqueous solution $(200 \mathrm{~mL})$ with a $\mathrm{pH}$ of 13.2 containing $\mathrm{Na}_{2} \mathrm{SO}_{3}(0.25 \mathrm{~mol} / \mathrm{L})$ and $\mathrm{Na}_{2} \mathrm{~S}(0.35 \mathrm{~mol} / \mathrm{L})$ as electron donors in the cell. The amount of $\mathrm{H}_{2}$ evolved was determined by sampling from the cell and test in a thermal conductivity detector (TCD) gas chromatography (Beifen-Ruili SP-2100, NaX zeolite column, nitrogen as a carrier gas). Blank experiments revealed that no hydrogen was produced without the catalyst being added or without light irradiation. The principle for evaluation of photocatalytic activity followed the reported description of Zhang [15].

\section{Conclusions}

Ultrasonic spray pyrolysis was successfully applied for the preparation of spherical particles. CdS spherical particles with different starting-solution concentrations and $\mathrm{Cu}$ doped $\mathrm{CdS}$ with doping levels of $0.2 \%, 0.5 \%$ and $1.0 \%$ have been considered to study the properties of photocatalytic hydrogen production. The optical absorption to UV-visible light, PL spectrum, morphology characteristics, XRF, XRD analysis and the hydrogen production rates were investigated. The photocatalytic activity of $\mathrm{CdS}$ has been improved by $\mathrm{Cu}$ doping and the optimal doping level was found to be $0.5 \mathrm{~mol} \%$ in the 
investigated range. In addition, a decreased band gap of CdS synthesized with this method was found and compared to typical value for bulk CdS sample. We ascribed the decrease of bandgap to defect levels formed in the band gap that originated from $\mathrm{Cd}$ vacancies. The enhancement of photocatalytic performance by $\mathrm{Cu}$ doping could result from the reducing of defect states by incorporating $\mathrm{Cu}$ elements, which take the positions of $\mathrm{Cd}$ vacancies. The spray pyrolysis is a convenient and effective method for preparing the doped CdS particles, which provide a solution-based technology platform to prepare large scale semiconductor composition or nanostructures for efficient photocatalytic applications.

Acknowledgments: This work was supported by the National Natural Science Foundation of China (No. 51236007) and the Fundamental Research Funds for the Central University (xjj2016039).

Author Contributions: S.J. conceived and designed the experiments; Z.T. performed the experiments; S.J., Z.T., L.Y., C.Y. and L.M. analyzed the data; Su J. wrote the paper.

Conflicts of Interest: The authors declare no conflict of interest.

\section{References}

1. Fujishima, A.; Honda, K. Electrochemical Photolysis of Water at a semiconductor Electrode. Nature 1972, 238, 37-38. [CrossRef] [PubMed]

2. Zhang, K.; Guo, L. Metal sulphide semiconductors for photocatalytic hydrogen production. Catal. Sci. Technol. 2013, 3, 1672-1690. [CrossRef]

3. Chen, Y.; Feng, X.; Liu, M.; Su, J.; Shen, S. Towards efficient solar-to-hydrogen conversion: Fundamentals and recent progress in copper-based chalcogenide photocathodes. Nanophotonics 2016. [CrossRef]

4. Chen, J.; Wu, X.; Yin, L.; Li, B.; Hong, X.; Fan, Z.; Chen, B.; Xue, C.; Zhang, H. One-pot Synthesis of CdS Nanocrystals Hybridized with Single-Layer Transition-Metal Dichalcogenide Nanosheets for Efficient Photocatalytic Hydrogen Evolution. Angew. Chem. Int. Ed. 2015, 54, 1210-1214. [CrossRef] [PubMed]

5. Vaquero, F.; Fierro, J.L.G.; Navarro Yerga, R.M. From Nanorods to Nanowires of CdS Synthesized by a Solvothermal Method: Influence of the Morphology on the Photoactivity for Hydrogen Evolution from Water. Molecules 2016, 21, 401. [CrossRef] [PubMed]

6. Sakimoto, K.K.; Wong, A.B.; Yang, P. Self-photosensitization of nonphotosynthetic bacteria for solar-to-chemical production. Science 2016, 351, 74-77. [CrossRef] [PubMed]

7. Yu, J.; Yu, Y.; Zhou, P.; Xiao, W.; Cheng, B. Morphology-dependent photocatalytic $\mathrm{H}_{2}$-production activity of CdS. Appl. Catal. B Environ. 2014, 156, 184-191. [CrossRef]

8. Xiang, Q.; Cheng, B.; Yu, J. Hierarchical porous CdS nanosheet-assembled flowers with enhanced visible-light photocatalytic $\mathrm{H}_{2}$-production performance. Appl. Catal. B Environ. 2013, 138, 299-303. [CrossRef]

9. Jin, J.; Yu, J.; Liu, G.; Wong, P.K. Single crystal CdS nanowires with high visible-light photocatalytic $\mathrm{H}_{2}$-production performance. J. Mater. Chem. A 2013, 1, 10927-10934. [CrossRef]

10. Zhang, N.; Yang, M.; Tang, Z.; Xu, Y. CdS-graphene nanocomposites as visible light photocatalyst for redox reactions in water: A green route for selective transformation and environmental remediation. J. Catal. 2013, 303, 60-69. [CrossRef]

11. Long, L.; Yu, X.; Wu, L.; Li, J.; Li, X. Nano-CdS confined within titanate nanotubes for efficient photocatalytic hydrogen production under visible light illumination. Nanotechnology 2014, 25, 035603. [CrossRef] [PubMed]

12. Fu, J.; Chang, B.; Tian, Y.; Xi, F.; Dong, X. Novel $\mathrm{C}_{3} \mathrm{~N}_{4}$-CdS composite photocatalysts with organic-inorganic heterojunctions: In situ synthesis, exceptional activity, high stability and photocatalytic mechanism. J. Mater. Chem. A 2013, 1, 3083-3090. [CrossRef]

13. Moriya, M.; Minegishi, T.; Kumagai, H.; Katayama, M.; Kubota, J.; Domen, K. Stable Hydrogen Evolution from CdS-Modified CuGaSe 2 Photoelectrode under Visible-Light Irradiation. J. Am. Chem. Soc. 2013, 135, 3733-3735. [CrossRef] [PubMed]

14. Lingampalli, S.R.; Gautam, U.K.; Rao, C.N.R. Highly efficient photocatalytic hydrogen generation by solution-processed $\mathrm{ZnO} / \mathrm{Pt} / \mathrm{CdS}, \mathrm{ZnO} / \mathrm{Pt} / \mathrm{Cd}_{1-\mathrm{x}} \mathrm{Zn}_{\mathrm{x}} \mathrm{S}$ and $\mathrm{ZnO} / \mathrm{Pt} / \mathrm{CdS}_{1}-{ }_{\mathrm{x}} \mathrm{Se}_{\mathrm{x}}$ hybrid nanostructures. Energy Environ. Sci. 2013, 6, 3589-3594. [CrossRef]

15. Zhang, K.; Jing, D.; Xing, C.; Guo, L. Significantly improved photocatalytic hydrogen production activity over $\mathrm{Cd}_{1-x} \mathrm{Zn}_{\mathrm{x}} \mathrm{S}$ photocatalysts prepared by a novel thermal sulfuration method. Int. J. Hydrog. Energy 2007, 32, 4685-4691. [CrossRef] 
16. Liu, M.; Jing, D.; Zhou, Z.; Guo, L. Twin-induced one-dimensional homojunctions yield high quantum efficiency for solar hydrogen generation. Nat. Commun. 2013, 4. [CrossRef] [PubMed]

17. Bao, N.; Shen, L.; Takata, T.; Domen, K. Self-Templanted Synthesis of Nanoporous CdS Nanostructures for Highly Efficienct Photocatalytic Hydrogen Production under Visible Light. Chem. Mater. 2008, 20, 110-117. [CrossRef]

18. Zang, J.; Zhao, G.; Han, G. Preparation of CdS Nanopaticles by Hydrothemal Method in Microemulsion. Front. Chem. China 2007, 2, 98-101. [CrossRef]

19. Murali, G.; Reddy, D.A.; Sambasivam, S.; Vijayalakshmi, R.P.; Reddy, V.R. CdS microflowers and interpenetrated nanorods grown on Si substrate: Structural, optical properties and growth mechanism. Mater. Chem. Phys. 2014, 146, 399-405. [CrossRef]

20. Tripathi, R.M.; Bhadwal, A.S.; Singh, P.; Shrivastav, A.; Singh, M.P.; Shrivastav, B.R. Mechanistic aspects of biogenic synthesisof CdS nanoparticles using Bacillus licheniformis. Adv. Nat. Sci. Nanosci. Nanotechnol. 2014, 5, 025006. [CrossRef]

21. Zhou, L.; Hu, X.; Wu, S. Effects of deposition temperature on the performance of CdS films with chemical bath deposition. Surf. Coat. Tech. 2013, 228, S171-S174. [CrossRef]

22. Okuyama, K.; Lenggoro, I.W.; Tagami, N.; Tamaki, S.; Tohge, N. Preparation of ZnS and CdS fine particles with different particle sizes by a spray-pyrolysis method. J. Mater. Sci. 1997, 32, 1229-1237. [CrossRef]

23. Huang, J.; Cheuk, W.; Wu, Y.; Lee, F.S.; Ho, W. Template-free synthesis of ternary sulfides submicrospheres as visible light photocatalysts by ultrasonic spray pyrolysis. Catal. Sci. Technol. 2012, 2, 1825-1827. [CrossRef]

24. Sunil, M.A.; Deepa, K.G.; Nagaraju, J. Growth of $\mathrm{AgInS}_{2}$ thin films by ultrasonic spray pyrolysis technique. Thin Solid Films 2014, 550, 71-75. [CrossRef]

25. Korake, P.V.; Achary, S.N.; Gupta, N.M. Role of aliovalent cation doping in the activity of nanocrystalline $\mathrm{CdS}$ for visible-light-driven $\mathrm{H}_{2}$ production from water. Int. J. Hydrog. Energy 2015, 40, 8695-8705. [CrossRef]

26. Chen, X.; Burda, C. The electronic origin of the visible-light absorption properties of C-, N- and S-doped $\mathrm{TiO}_{2}$ nanomaterials. J. Am. Chem. Soc. 2008, 130, 5018-5019. [CrossRef] [PubMed]

27. Huang, S.; Lin, Y.; Yang, J.; Li, X.; Zhang, J.; Yu, J.; Shi, H.; Wang, W.; Yu, Y. Enhanced photocatalytic activity and stability of semiconductor by Ag doping and simultaneous deposition: The case of CdS. RSC Adv. 2013, 3, 20782-20792. [CrossRef]

28. Xie, R.; Su, J.; Li, M.; Guo, L. Structural and Photoelectrochemical Properties of Cu-Doped CdS Thin Films Prepared by Ultrasonic Spray Pyrolysis. Int. J. Photoenergy 2013. [CrossRef]

29. Rmili, A.; Ouachtari, F.; Bouaoud, A.; Louardi, A.; Chtouki, T.; Elidrissi, B.; Erguig, H. Structural, optical and electrical properties of Ni-doped CdS thin films prepared by spray pyrolysis. J. Alloy. Compd. 2013, 557, 53-59. [CrossRef]

30. Tauc, J. Amorphous And Liquid Semiconductors; Plenum Press: London, UK, 1974.

31. Cortes, A.; Gomez, H.; Marotti, R.E.; Riveros, G.; Dalchiele, E.A. Grain size dependence of the bandgap in chemical bath deposited CdS thin films. Sol. Energy Mater. Sol. Cells 2004, 82, 21-34. [CrossRef]

32. Wei, S.; Zhang, S.; Zunger, A. First-principles calculation of band offsets, optical bowings, and defects in CdS, CdSe, CdTe, and their alloys. J. Appl. Phys. 2000, 87, 1304. [CrossRef]

33. Scherrer, P. Estimation of the size and internal structure of colloidal particles by means of röntgen. Nachr. Ges. Wiss. Göttingen 1918, 2, 96-100.

34. Mandal, P.; Talwar, S.S.; Major, S.S.; Srinivasa, R.S. Orange-red luminescence from Cu doped CdS nanophosphor prepared using mixed Langmuir-Blodgett multilayers. J. Chem. Phys. 2008, 128, 114703. [CrossRef] [PubMed]

35. Wang, L.; Huang, S.; Sun, Y. Low-temperature synthesis of hexagonal transition metal ion doped ZnS nanoparticles by a simple colloidal method. Appl. Surf. Sci. 2013, 270, 178-183. [CrossRef]

36. Nakanishi, T.; Ohtani, B.; Uosaki, K. Fabrication and char-acterization of CdS-nanoparticle mono- and multilayers on a self-assembled monolayer of alkanedithiols on gold. J. Phys. Chem. B 1998, 102, 1571-1577. [CrossRef]

37. Wang, Y.; Suna, A.; Mahler, W.; Kosowski, R. PbS in polymers. From molecules to bulk solids. J. Chem. Phys. 1987, 87, 7315-7322. [CrossRef]

38. Chen, H.; Huang, X.; Xu, L.; Xu, J.; Chen, K.; Feng, D. Self-assembly and photoluminescence of CdS-mercaphtoacetic clusters with internal structures. Superlattice Microst. 2000, 27, 1-5. [CrossRef] 
39. Chen, W.; Xu, Y.; Lin, Z.; Wang, Z.; Lin, L. Formation, structure and fluorescence of CdS clusters in a mesoporous zeolite. Solid State Commun. 1998, 105, 129-134. [CrossRef]

40. Costa, V.C.; Shen, Y.; Bray, K.L. Luminescence properties of nanocrystalline CdS and CdS: $\mathrm{Mn}^{2+}$ doped silica-type glasses. J. Non-Cryst. Solids 2002, 304, 217-223. [CrossRef]

41. Panda, R.; Rathore, V.; Rathore, M.; Shelke, V.; Badera, N.; Sharath Chandra, L.S.; Jain, D.; Gangrade, M.; Shripati, T.; Ganesan, V. Carrier recombination in $\mathrm{Cu}$ doped CdS thin films: Photocurrent and optical studies. Appl. Surf. Sci. 2012, 258, 5086-5093. [CrossRef]

42. Abe, T.; Kashiwaba, Y.; Baba, M.; Imai, J.; Sasaki, H. XPS analysis of p-type Cu-doped CdS thin films. Appl. Surf. Sci. 2001, 175, 549-554. [CrossRef]

43. Kashiwaba, Y.; Kanno, I.; Ikeda, T. p-Type characteristics of Cu-doped CdS thin films. Jpn. J. Appl. Phys. 1992, 31, 1170-1175. [CrossRef]

Sample Availability: All samples are available from the authors.

(C) 2016 by the authors; licensee MDPI, Basel, Switzerland. This article is an open access article distributed under the terms and conditions of the Creative Commons Attribution (CC-BY) license (http://creativecommons.org/licenses/by/4.0/). 